\title{
CURRÍCULO QUESTÕES INICIAIS: ATUACC̃̃O DO EDUCADOR E A FORMAÇÃO DO CIDADÃO CRÍTIÇO E REFLEXIVO
}

\author{
Isac Oliveira Brito* \\ Marcelo Máximo Purificação**
}

RESUMO: O currículo, a partir do momento em que passou a ser considerado como um campo de estudo, sendo inserido no contexto pedagógico, tem passado por grandes modificações e/ou definições, principalmente em seu real objetivo. Assim, este trabalho, desenvolvido com base em meios investigativos de caráter bibliográfico e documental, de natureza básica e abordagem qualitativa visa dialogar acerca dos documentos e bibliografias afins, buscando relacionar objetivos da educação com relação à formação do indivíduo crítico e reflexivo com as propostas do currículo escolar prescrito. Tem ainda, como linha de diálogo, a prática docente referente à aplicação e construção desse currículo, bem como a inserção, quando e se necessário, do currículo oculto, visando manter atenção especial para a realidade social diversificada que hoje podemos vivenciar. Desse modo, esta pesquisa integrará, no decorrer de seu desenvolvimento, alguns pontos, apontando momentos propícios para a reflexão docente, com a finalidade de melhoria contínua da educação, tais como: os modelos de currículos trabalhados na atualidade, dentro de uma visão nacional e posteriormente fragmentada, focando o modelo prescrito e suas ramificações, o currículo oculto e sua importância durante a prática pedagógica e a atuação do educador enquanto agente de formação de cidadãos críticos e reflexivos.

PALAVRAS-CHAVE: Currículo; Educação; Prática docente; Realidade social.

\section{FIRST ISSUES ON THE CURRICULUM: THE EDUCATOR AND THE FORMATION OF A CRITICAL AND REFLEXIVE CITIZEN}

ABSTRACT: Since it has become a study object and inserted within the pedagogical context, the curriculum has undergone several modifications and definitions, especially with regard to its true aim. Current bibliographical, documental and quality analysis discusses documents and related bibliographies to link educational

Graduado em Pedagogia Centro Universitário de Mineiros (UNIFIMES), Brasil.

* Pós-Doutor Júnior em Educação pela Faculdade de Psicologia e Educação da Universidade de Coimbra. Docente Adjunto no Centro Universitário de Mineiros (UNIFIMES), Brasil. E-mail: maximo@fimes.edu.br 
aims and the formation of the critical and reflexive individual within the contexts of the proposal of the school curriculum. There is also the teaching practice, or rather, the application and construction of the curriculum and the insertion, when and if required, of the hidden curriculum to give special attention to current diversified social reality. Current research integrates certain issues for teachers' ${ }^{\prime}$ reflection for the continuous improvement of education, such as, curriculum models fabricated within a national environment and later fragmented, focusing the prescribed model and its branches, the hidden curriculum and its importance during pedagogical practice and the educators' activities as a formation agent of critical and reflexive citizens.

KEY WORDS: Curriculum; Education; Teaching practice; Social reality.

\section{INTRODUÇÃO}

O currículo, definido pelo Dicionário Houaiss (2001, s/p), como "programação de um curso ou de matéria a ser examinada", e ainda, como "Conjunto de disciplinas sobre um determinado curso ou programa de ensino ou a trajetória de um indivíduo para o seu aperfeiçoamento profissional", pelo Dicionário Interativo da Educação Brasileira ${ }^{3}$, vem, conforme seu contexto histórico, se adequando às novas necessidades e conceitos de educação. Moreira e Candau (2006) define currículo como sendo "o conjunto de esforços pedagógicos promovidos na escola, com o propósito de organizar e tornar efetivo o processo educativo". E às Diretrizes Curriculares Gerais para a Educação Básica, (2013), como "um instrumento político, cultural e científico formulado com base em uma construção coletiva".

Tomando por base as questões norteadoras, percebe-se que o currículo permeia a prática docente em seus grandes modelos; no entanto, segundo Tomaz Tadeu da Silva (2007) "é impossível abordá-lo apenas pelos enfoques de conceitos técnicos de ensino e eficiência”, pois, o ensino é um campo de estudo de várias ciências ligado ao conhecimento e nesse contexto, o currículo e sua ação legitima e postula a qualidade do ensino.

Contextualizando o cenário histórico do currículo, a partir das concepções

\footnotetext{
Disponível em: http://www.educabrasil.com.br/curriculo/. Acesso em: 13 de set. 2017.
} 
de Saviani (2007) em sua célebre obra, história das ideias pedagógicas no Brasil, notase que foi a partir da década de 1960, com o nacional desenvolvimentismo proposto pelo então presidente JK, que o tecnicismo instalou-se no Brasil, materializado na corrente tecnicista da educação, fazendo do currículo algo que colaborasse para o Capitalismo com a colocação do maior número de alunos no mercado de trabalho. A educação era baseada em um currículo voltado para a obtenção de força de trabalho fragmentada, características do taylorismo, então em alta na Europa e nos Estados Unidos, ou seja, reduzia o acesso dos alunos ao vasto conhecimento existente, se tornando algo desinteressante para a grande maioria, tendo em vista que os que se sobressaíam economicamente bem, eram os mais favorecidos, caracterizando um modelo curricular tecnicista (AZEVEDO, 2015).

Já entre o final da década de 1960 e início da década de 1970, um modelo curricular voltado para uma visão mais crítica, começa a surgir, principalmente a partir do trabalho de Paulo Freire, período em que os filósofos iniciam uma busca por igualdade social, visando - através do currículo - uma maneira de aproximação com os assuntos de interesse das classes menos favorecidas, tornando a educação mais acessível e abrangente, independente da classe social a que se destinava. Nesse contexto, Paulo Freire foi "a voz mais incisiva contra a forma de definir e organizar o currículo e os conteúdos disciplinares e contra a forma de transmiti-los" (MORAES; KÜLLER, 2016, p. 29-31).

Com isso, no Brasil começa uma busca de adequação da educação a essas novas classes admitidas no sistema escolar, submetendo-o a transformações necessárias para que pudesse acompanhar todo o fluxo de evolução, ou seja, a escola começou a buscar meios de atender a essas grandes mudanças, dando foco a um novo formato de currículo 'mais crítico' - embasado na pedagogia históricocrítica propagada por Saviani (2013) - que pudesse atender à população de forma mais ampla, dando oportunidade de diálogo frente às novas problemáticas, principalmente sociais e econômicas.

Isto posto, colocamos no centro do diálogo as contribuições de alguns teóricos como por exemplo Arroyo (2013), Cool (1997), Küller (2016), Saviani (2007) entre outros, bem como nossa Lei de Diretrizes e Bases da Educação - LDB como fundamentação para pensarmos em melhorias contínuas possíveis no que 
se trata da formação eficaz dos educandos, possibilitando sua transformação em agentes críticos e reflexivos da sociedade na qual vivem.

\section{CURRÍCULO PRESCRITO E OPORTUNIDADES DE MELHORIAS SOB UMA VI- SÃO CRÍTICA E REFLEXIVA DOS EDUCADORES}

Sobre a expressão "sistema educacional" refere-se aqui ao currículo escolar prescrito que, por mais que esteja sendo adequado para que seja atendida a necessidade social, ainda deve ser olhado com bastante atenção.

O currículo prescrito se caracteriza pelo conjunto de decisões normativas de cunho nacional, estadual e municipal de educação. Enquanto em uma visão nacional, mais abrangente, ele é pensado e definido sob a escolha de eixos comuns a serem trabalhados por todas as instituições; já em uma visão estadual, municipal e institucional, ele é trabalhado com base nos eixos comuns definidos pela lei nacional, porém com a orientação de que sejam acrescentados temas específicos caros a cada localidade. Conforme rege a LDB 9394/96, 1996, em seu Art. 26):

Os currículos da educação infantil, do ensino fundamental e do ensino médio devem ter base nacional comum, a ser complementada, em cada sistema de ensino e em cada estabelecimento escolar, por uma parte diversificada, exigida pelas características regionais e locais da sociedade, da cultura, da economia e dos educandos. (Redação dada pela Lei $n^{0} 12.796$, de 2013).

Para uma compreensão mais detalhada, podemos dizer que o currículo é um conjunto de conteúdos que são definidos em esfera nacional, e que, ao chegar no estado, deverá ser atendido, porém, o estado em questão acrescentará itens específicos de sua cultura. Essa adequação realizada pelo estado chegará aos seus municípios, que também farão as adequações para atendimento da sua realidade, e assim sucessivamente até chegar nas instituições de cada um dos municípios que, por sua vez, também farão suas adequações, de acordo com o público ao qual atendem (DIRETRIZES CURRICULARES NACIONAIS GERAIS DA EDUCAÇÃO BÁSICA, 2013, p. 32).

Ao elaborar e analisar este modelo de currículo, é necessário que tudo seja feito através de uma visão sensível, ao qual será importante para a formação dos 
indivíduos enquanto cidadãos críticos e reflexivos, e à realidade social e cultural em que estão inseridos, porém não deixando de lado os conhecimentos de outras culturas e nações, conforme é citado em nosso PCN quanto às capacidades a serem desencadeadas nos educandos.

Os Parâmetros Curriculares Nacionais indicam como objetivos do ensino fundamental que os alunos sejam capazes de: Conhecer e valorizar a pluralidade do patrimônio sociocultural brasileiro, bem como aspectos socioculturais de outros povos e nações, posicionando-se contra qualquer discriminação baseada em diferenças culturais, de classe social, de crenças, de sexo, de etnia ou outras características individuais e sociais (BRASIL, 1997, p. 6).

O conhecimento transmitido e discutido não deve se resumir apenas ao que está ao alcance desse indivíduo, embora todo seu saber deva ser valorizado, ou seja, o meio social dos sujeitos deve indispensavelmente ser apreciado e incluído nas práticas educativas, mas isso não quer dizer que os demais meios não devam ser analisados e trazidos ao debate, como meio de ampliação da cultura e aquisição de conhecimento.

Mas como, a cunho nacional, essas particularidades sociais são vistas a tempo de serem inseridas no currículo? Na realidade, para que uma situação ou assunto seja considerado nacionalmente importante e tornar-se conteúdo comum, ele deverá apresentar traços que sejam pertinentes em nível nacional, ou melhor, deverá abranger uma necessidade/interesse nacional, não apenas local.

Nas concepções de Saviani (2013), o currículo é entendido como forma de produção, organização e registro do saber escolar. E Moraes e Küller (2016, p. 39) "o compreende como conjunto sistematizado e organizado didaticamente dos campos de conhecimento que todos devem conhecer". Um currículo, que se caracteriza como sendo o modelo de currículo apresentado por diferentes instâncias, onde os municípios e os estados participam desse construto, a fim de elaborar um modelo nacional.

Modelo curricular traduzido, que se refere ao ato de adequar várias propostas parecidas, enviadas por mais de um município, porém com algumas divergências ou diferentes linguagens, criando-se um modelo onde todas estas propostas são atendidas, sob uma linguagem unificada; ou seja: uma Base Nacional Comum. 
Ainda segundo Moraes e Küller (2016), podemos citar o modelo curricular trabalhado, que diz respeito às atividades escolares - ideias e metas que ganham corpo e são aceitas no núcleo nacional e que está intimamente ligado ao currículo concretizado que - por sua vez - é aquele modelo aprovado pelo fato de abranger um conjunto de efeitos cognitivos, afetivos, morais e sociais sobre os alunos e que se torna, então, apropriado para ser aprovado e concretizado.

Diante do exposto, nota-se que há possibilidades das escolas, municípios e estados darem corpo às necessidades locais, por meio de sua participação individual, porém, deverão se atentar ainda ao atendimento aos aspectos contextual, procedimental e atitudinal em meio aos conteúdos propostos, não exercendo um papel educativo que sirva apenas para a escola. Moraes e Küller (2016, p. 40) reforçam que

é preciso partir da negação de que o objetivo da escola é a transmissão de um saber que só serve para a escola e só tem sentido dentro do seu sistema de avaliação (provas e exames) e progressão (passar de ano). Se considerarmos como fins da escola a preparação do aluno para a vida, incluindo nela a preparação para o trabalho, o papel da educação escolar passa a ser o desenvolvimento, a relação interpessoal, a vida em sociedade e o trabalho produtivo. $\mathrm{O}$ que se busca são resultados para a vida do aluno, para o seu desempenho no trabalho, sua atuação política, sua relação consigo mesmo, sua convivência amorosa com o outro.

Subentende-se a partir do exposto que o currículo deve extrapolar a palavra morta no papel e ser realmente uma ferramenta de transformação.

$\mathrm{Na}$ linha dessas ideias, Cool (1997), enfatiza que os conteúdos contextuais são "o que aprender", ou seja, os conteúdos que devem ser transmitidos aos alunos, devendo abranger o contexto, a realidade em que eles vivem, calcar em estudos direcionados. Já os procedimentais são o "como aprender" - através de que técnicas, de quais instrumentos os alunos devem chegar ao aprendizado. Devem-se, então, obter bons métodos de como serão aplicados esses conteúdos. E, por fim, os aspectos atitudinais do currículo, que se resumem na questão de como o aluno deve agir, quais atitudes deve ter, como ele deve ser, ora, formando-o, capacitando-o para ter atitudes acerca da sociedade, seja sob uma linha pessoal ou profissional, refletindo e criticando positivamente. 
Nesta pesquisa buscamos ainda perpassar por exemplos de situações onde fossem possíveis identificar fatores, que, de maneira não muito complexa, possam ser trabalhados por meio da atuação consciente dos profissionais da área da educação, ou até mesmo sob uma revisão curricular mais crítica, onde não apenas os interesses governamentais sejam atendidos, mas juntamente com isso, esteja presente a participação do educador como parte construtora do currículo, uma vez que ele, devido ao contato mais aproximado, que se espera desse profissional, deve ter uma noção maior do que promoverá prazer, curiosidade e eficácia durante as aulas, bem como o protagonismo do próprio aluno, uma vez que, se tratando de sua formação crítica e reflexiva, isso se dará por meio do resultado proveniente da autonomia por ele conquistada, mediante desafios propostos em sala de aula.

Paulo Freire (2015) pontua que um dos problemas do currículo é a falha que se dá ao designar os conteúdos e - ao mesmo tempo - também pelo despreparo dos profissionais.

Diante disso, embora os planos curriculares de um determinado país, estado, município ou unidade educacional possam ser classificados como bons em termos gerais esperados, é necessário primeiramente que os profissionais aos quais será repassada a responsabilidade de ministração desses conteúdos, estejam preparados para discorrer sobre eles em sala de aula, sem deixar de apontar também a importância de que o estabelecimento dos conteúdos a serem trabalhados seja analisado por pessoas também qualificadas.

Arroyo (2013, p. 24) observa o seguinte:

parece estranho, mas as artes de educar nem sempre estiveram presentes em nossa formação. O ser educador(a), a identidade educadora nem sempre fez parte de nossa identidade profissional. Quando no cotidiano das salas de aula, no convívio e nas relações com os alunos precisamos recorrer às artes de educar nos sentimos carentes de seus domínios. Despreparados.

$\mathrm{Na}$ citação acima, trata-se do despreparo do professor durante a prática docente. Esse "sentir-se despreparado" pode advir de uma fragilidade da grade curricular, oferecida na própria formação desse profissional ou, ainda, por ele não buscar - ter buscado - melhoras para sua formação, através de formação continuada ou mesmo leituras atualizadas sobre os temas que lhe dizem respeito. 
Ao falarmos de currículo fica evidente a sua abrangência. É como imaginarmos um ciclo onde há vários componentes, um ligado ao outro para fechar um objetivo traçado, um dependendo do outro para prosseguir com o processo de cumprimento das metas, devendo cada um desses elementos funcionar da maneira mais adequada possível. Se um falha, ou a meta fracassa ou é dificultada sua concretização para os demais integrantes.

O currículo escolar, de maneira geral, se caracteriza como componente que contribui para uma organização dos conteúdos a serem aplicados, tomando como base o que afirma Pacheco (2001, p. 16) "o currículo associa-se a um plano de estudos, ou a um programa estruturado e organizado na base de objetivos, conteúdos e atividades de acordo com a natureza das disciplinas".

Desse modo, visa padronizar o conhecimento sistematizado de forma racional dentro dos princípios sociais, políticos e econômicos, onde não somente a organização será levada em conta, mas também a articulação, aplicação e avaliação desses conteúdos.

Entretanto, o sistema educacional, enquanto norteador dos componentes curriculares, segundo Saviani (2013) deve ser sempre pensado, organizado, avaliado e aplicado sob uma perspectiva de que - a qualquer momento - haverá a necessidade de revisão, como consequência natural da evolução e transformação contínua da sociedade e/ou demais fatores que econômica, tecnológica ou politicamente poderão, direta ou indiretamente nela interferir.

Colocando em evidência essa transformação social contínua, entendemos que o público discente deverá estar também sendo condicionado dentro do âmbito escolar, a viver essas fases pós-evolução, de maneira que possa dialogar, entender e pensar, de forma crítica e reflexiva, como consequência da não estagnação curricular ou até mesmo profissional, por parte dos educadores.

Para isso, vemos ainda, que é necessário que a escola e profissionais da área, através de seu poder de transformação, estejam em sintonia com as mudanças e evoluções sociais e, ao mesmo tempo, deem aos alunos oportunidade de se manifestarem enquanto sujeitos ativos e críticos diante dos problemas de sua sociedade, possibilitando sua participação enquanto cidadãos atuantes, nas decisões conscientes para a transformação da sua sociedade, superando as desigualdades sociais. 
Sacristán (1999, p. 61) afirma que

o currículo é a ligação entre a cultura e a sociedade exterior à escola e à educação; entre o conhecimento e cultura herdados e a aprendizagem dos alunos; entre a teoria (ideias, suposições e aspirações) e a prática possível, dadas determinadas condições.

Em outras palavras, o currículo deverá ser pensado de forma que o novo ${ }^{4}$ se faça presente, e que mesmo de forma gradativa, vá oportunizando uma conexão inovadora e aberta às novas formas de pensar.

Ao mesmo tempo, o profissional da educação deverá estar em constante busca de capacitação, através de formação continuada, que não significa apenas participações em eventos, mas aquela que se caracteriza pelos estudos que o educador pode fazer em sua própria casa, a fim de munir-se de conhecimentos; se permitindo entender e levar aos seus alunos o entendimento e a capacidade de refletir sobre a realidade atual, dentro e fora da escola, viabilizando ao mesmo tempo, um possível diálogo comparativo com o velho ${ }^{5}$, e, favorecendo também as análises sobre revisões futuras de práticas atuais, como meio de melhoria contínua (Diretrizes Curriculares Gerais para a Educação Básica, 2013).

Desse modo, Gasparin (2012) chama atenção para a visão da prática dos conteúdos curriculares educacionais e a transposição didática para sala de aula, fato que exigirá uma visão crítica e consciente dos profissionais da educação, ao interferirem na elaboração ou revisão do currículo. Embora essa organização seja de cunho nacional, os gestores têm ou pelo menos devem ter, diante do exposto neste artigo, grande influência nessa elaboração, devendo cada um deles estarem esclarecidos sobre a realidade social do público de suas escolas e, ao mesmo tempo, buscando ativamente recursos e meios técnicos para que essa realidade seja atendida durante a prática educativa.

Trazendo brevemente à discussão a realidade social brasileira dentro do âmbito escolar, apresentamos hipoteticamente duas situações: todo tempo nos deparamos com situações delicadas e/ou ainda desumanas, como por exemplo as diversas crianças que crescem sem família (entendida aqui no modelo tradicional

Novas situações provenientes da evolução ou transformação da sociedade ou demais fatores que possam nela interferir.

5 Situações ou formas de pensar consideradas defasadas, antigas. 
ou moderno, composta por familiares, biológicos ou não), algumas nas ruas ou em casas amparadoras. Ainda como exemplo, podemos citar os casos em que, em uma única escola, estudam crianças de famílias distintas que possuem enormes diferenças econômicas.

Seguindo a linha desses dois exemplos, para Gaspar \& Roldão (2007, p.39) "o currículo em ação faz emergir o desenvolvimento escolar", assim, para ambos os casos, o sistema, ou até mesmo a escola (referindo-se aqui aos educadores), deverão estar preparados, tanto sobre a forma de aplicação dos conteúdos, quanto na qualificação dos profissionais que deverão saber lidar com essas situações, para que haja evolução escolar e, posteriormente, efeito na sociedade.

Caso ocorra o contrário, ou seja, se o currículo não possuir meios de embasamento para o educador atuar diante de diferentes situações, poderá haver uma forma de exclusão, enquanto o que se espera é que haja inclusão, que impacte positivamente na sociedade, gerando mudanças de posturas, caracterizadas pela ampliação da visão de mundo, realidade e reflexão.

Por outro lado, ao mesmo tempo que os professores devem ter a consciência de que devem estar preparados, tanto para aplicação dos conteúdos quanto para dialogarem sobre os temas reais e atuais, que permeiam a sociedade na qual estão inseridos (ou seja, classificação social e cultural), eles também devem ser ouvidos, valorizados no que diz respeito à elaboração do currículo (GASPAR; ROLDÃO, 2007).

Pressupondo que o professor conheça bem o meio no qual atua, que saiba dialogar sobre este mesmo meio, criticar e refletir sobre os problemas que estão evidentes, devido ao vasto conhecimento adquirido ao longo do tempo, durante a relação com os educandos, por que negar-lhe um lugar, voz na definição/construção do currículo que será destinado para este ambiente?

Arroyo, (2013, p. 71) coloca que

os saberes da docência e os próprios docentes-trabalhadores têm estado ausentes nos conhecimentos escolares. Os currículos acumulam muitos saberes, mas sabem pouco dos adultos que os ensinam e menos ainda das crianças, adolescentes e jovens que os aprendem. O curioso é que tanto os mestres quanto os educandos têm propiciado um acúmulo riquíssimo de vivências e de estudos, de conhecimentos, teses, narrativas e histórias do magistério, da infância, da adolescência e da juventude. Sujeitos de história, mas sem direito de conhecer sua história. 
À vista disso, corre-se o risco de ficar uma lacuna a ser preenchida com relação à elaboração do currículo. Pode ser que haja muito o que melhorar, partindo do ponto de vista de que os educadores e educandos, podendo acrescentar-se ainda pais e responsáveis, possam ter uma participação maior, se comparada à situação atual na elaboração do currículo, em que seus ideais sejam reconhecidos quando pertinentes.

Porém, os indivíduos, enquanto precisarem ser, de fato, sujeitos de uma transformação social positiva, com base na educação, deverão estar intimamente ligados à sociedade à qual pertencem, uma vez que, para podermos criticar e refletir diante de um fato social, é necessário que saibamos - conheçamos bem - o meio em que vivemos. Daí dar-se-á a possibilidade de diálogo entre todas as esferas participantes da sociedade (ARROYO, 2013).

\section{O CURRÍCULO REAL E OCULTO}

O currículo prescrito, embora seja pensado e elaborado para atender à amplitude nacional e possuir grande importância, por oferecer uma organização dos conteúdos em nível nacional, mantendo/possibilitando um diálogo coerente entre as regiões, ele acaba não sendo um manual onde estão previstas todas as diversidades presentes ou futuras, em sala de aula, ou fora dela.

Percebe-se que, para que haja uma aplicação adequada dos conteúdos, o currículo deve ser pensado a partir de uma reflexão sobre a sociedade na qual ele está ou estará sendo inserido; não existiria currículo sem sociedade. Embora cada região possua suas tendências sociais particulares, o currículo deverá estar sempre calcado em pontos comuns nacionais, porém, poderá ser adequado de acordo com os pontos regionais, caracterizando um outro modelo curricular, chamado de currículo real, sem que sua essência macro seja abalada ${ }^{6}$, garantindo uma aplicação dos conteúdos que atenderá, ao mesmo tempo, de maneira satisfatória, a realidade social da região, porém embasada em uma visão mais técnica, pensada e elaborada sob o olhar nacional.

\footnotetext{
Desviar ou ir contra o sentido ou objetivo geral proposto pelo Parâmetro Curricular Nacional (PCN).
} 
Além desses modelos de currículos já citados anteriormente, destacamos o currículo oculto, que é assim considerado por não estar claramente evidenciado, "não é prescrito, não aparece no planejamento, embora constitua importante fator de aprendizagem" (LIBÂNEO; OLIVEIRA apud PLATT; ABRAHÃO, s/d, p. 177).

Para Silva (2007) o currículo oculto é constituído por todos aqueles aspectos do ambiente escolar que, embora não façam parte do currículo oficial explícito, contribuem para aprendizagens sociais relevantes.

Camacho, (2010 p. 9) acrescenta que, mesmo este modelo curricular não estando expresso em nenhum documento oficial, ele obtém grande importância para a formação crítica e reflexiva do aluno, uma vez que se apropria de valores e crenças e também de orientações que o fazem perceber seu papel, tanto em sala de aula quanto na sociedade, atual e futura.

Nesta forma de aplicar conteúdos ocultos, destacam-se também os gestos, vocabulários e comportamentos que acabam tendo destaque no meio social e escolar - trazido para o meio com objetivos educacionais, ou melhor dizendo, utilizado pelo educador na maioria das vezes para manter uma certa aproximação com o corpo discente, a fim de obter bons resultados.

Assim, novamente colocando em discussão a atuação do educador, cabe a ele analisar sua nação, região, município, escola, sala de aula e por fim aluno, bem como a sociedade na qual cada um destes itens está inserido.

O currículo prescrito, mesmo sendo organizado e pensado para a nação, conforme já citado, não consegue suprir todas as demandas, e com uma boa análise dos educadores antes ou até mesmo durante a atuação é possível que as lacunas (surpresas referentes à diversidade ou fatos relevantes que não estão presentes no currículo prescrito) sejam preenchidas, por meio de uma elaboração coletiva de um currículo real (amplamente discutido) para que haja, por parte da instituição, uma boa aplicação do currículo, onde se permeie um olhar crítico, reflexivo e criativo do educador ao propor soluções em forma de aula.

\section{CONSIDERAÇÕES FINAIS}

A título de considerações finais, percebe-se que o currículo previamente pensado ou prescrito, atua como norteador dos conteúdos que eram transmitidos 
aos alunos, com o objetivo de gerar e manter uma certa ordem com relação à educação. Ele tem grande importância na obtenção dos bons resultados educacionais esperados, como por exemplo a formação de um cidadão crítico e reflexivo, para que este, enquanto indivíduo atuante e ativo, seja capaz de lidar com as tendências sociais, bem como com a própria e real sociedade na qual está inserido.

O aluno, sendo preparado adequadamente para uma atuação social crítica e reflexiva, estará apto a coloborar, de forma participativa com a sociedade, seja na luta por melhorias, direitos, etc., seja na construção de uma sociedade mais humana, justa e, acima de tudo, democrática.

Esta atuação ativa do cidadão crítico e reflexivo irá gerar o que se espera, uma transformação social, em que - com base em atitudes conscientes e maneiras de pensar produtivas - sejam entendidas e tratadas as fragilidades sociais e também econômicas e políticas, pois se temos um cidadão atuante, ativo, crítico que saiba refletir e dialogar diante de situações incômodas presentes na sociedade, o meio político opressor, quando assim caracterizado, o impedirá de agir dessa maneira, uma vez que encontrará barreiras utilizadas de forma legal para impedi-lo.

Dito isso, como entraria o currículo oculto nas possíveis soluções ou contribuições para a formação crítica e reflexiva do indivíduo? Sabemos que, mesmo a escola e a família fazendo sua parte, a sociedade sempre fará a sua, destacando aqui um ponto de vista negativo da sociedade, trazendo em evidência o fato de que a maioria dos assassinos, pedófilos, entre outros, também passaram por um sistema educacional na infância e adolescência. Por isso, é preciso que o educador preencha as lacunas educativas com sua atuação consciente e, ao mesmo tempo, criativa.

A consciência e criatividade que se espera do educador, dentro de uma sala de aula, é no sentido de que, ao mesmo tempo que saiba de sua importância e do quanto pode contribuir para melhorar continuamente a sociedade, saiba também utilizar o que tem em mãos com relação ao conteúdo, material, método e espaço, buscando inovações para a práxis, não se fixando apenas no que é proposto como modelo, mas complementando com sua criatividade, diversificando as formas de atuação, de acordo com a realidade de suas turmas, e pensando no futuro de seus alunos e de sua própria sociedade.

O educador tem o poder de mudar a sociedade, para melhor mas também para pior. Seu papel, sua prática, devem gerar em seus alunos a capacidade de crítica 
e reflexão; no entanto, isso deve primeiramente ser feito de forma também crítica e reflexiva.

\section{REFERÊNCIAS}

ARROYO, M. G. Currículo, território em disputa. 5. ed. Petrópolis, RJ: Vozes, 2013.

AZEVEDO, M. J. C. Biologia experimental, experimentação na Biologia escolar e o manual do professor de Biologia do Biological Science Curriculum Study (BSCS): estudo de relações sócio históricas. 2015. Tese (Doutorado) - Faculdade de Educação da UFF, Niterói, RJ.

BRASIL. Lei n. 9394, 20 de dezembro de 1996. Lei de Diretrizes e Bases da Educação Nacional.

BRASIL. Parâmetros Curriculares Nacionais: apresentação dos temas transversais, ética/ Secretaria de Educação Fundamental. Brasília: MEC/SEF, 1997.

BRASIL. Ministério da Educação. Secretaria de Educação Básica. Secretaria de Educação Continuada, Alfabetização, Diversidade e Inclusão. Conselho Nacional da Educação. Diretrizes Curriculares Nacionais Gerais da Educação Básica. Ministério da Educação. Secretaria de Educação Básica. Diretoria de Currículos e Educação Integral. Brasília: MEC, SEB, DICEI, 2013.

CAMACHO, R. C. S. As Repercussóes do Currículo oculto na sociedade. 2010. Disponível em: < http://pt.slideshare.net/rakellcsc/curriculo-oculto $>$. Acesso em: 04 nov. 2016.

COLL, C. Psicologia e Currículo: uma aproximação psicopedagógica à elaboração do currículo escolar. São Paulo: Ática, 1997. 
GASPAR, I.; ROLDÃO, M. do C. Elementos de Desenvolvimento curricular. Lisboa: Universidade Aberta, 2007.

GASPARIN, J. L. Uma Didática para a Pedagogia Histórico-crítica. 5. ed. Campinas: Autores Associados, 2012.

HOUAISS, A. Dicionário Eletrônico Houaiss da Língua Portuguesa. São Paulo: Objetiva, [2001]. 1 CD-ROM

MORAES; KÜLLER. Currículos Integrados: no ensino médio e na educação profissional. Desafios, experiências e propostas. São Paulo: Senac São Paulo, 2016.

PACHECO, J. A. Currículo: teoria e práxis. [s.1.]: Porto, 2001.

PLATT, D. A.; ABRAHÃO, L. T. S. Gestão escolar, Currículo e PPP: análise aos eixos filosóficos fundamentais para a construção da rotina escolar. 173-186. S/D.

SACRISTÁN, J. G. O Currículo: uma reflexão sobre a prática. Porto Alegre: Artmed, 2000 .

SACRISTÁN, J. G. Poderes instáveis em Educação. Porto Alegre: Artmed, 1999.

SAVIANI, D. História das ideias pedagógicas no Brasil. Campinas: Autores Associados, 2007.

SILVA, T. T. da. Documentos de Identidade: uma introdução às teorias do currículo. 2. ed. Belo Horizonte: Autêntica, 2007.

VELASCO, D. B. "Realidade do Aluno", “Cidadão Crítico", "Conhecimento Escolar": que articulações possíveis no Currículo de História? 2013. Dissertação (Mestrado em Educação) - Faculdade de Educação, Universidade Estadual do Rio de Janeiro, RJ. 
Recebido em: 08 de julbo de 2017

Aceito em: 04 de outubro de 2017 